\title{
ANALISIS KANDUNGAN ZAT PENGAWET NATRIUM BENZOAT PADA SAMBAL TRADISIONAL KHAS BIMA “MBOHI DUNGGA" SAMBAL JERUK YANG DIFERMENTASI
}

\author{
Sri Wahyuningsih $\mathbb{( i}^{1)}$ dan Nurhidayah $\mathbb{( B D}^{2)}$ \\ ${ }^{1}$ Kesehatan Lingkungan, Sekolah Tinggi Teknik Lingkungan Mataram \\ ${ }^{2}$ Teknik Lingkungan, Sekolah Tinggi Teknik Lingkungan Mataram \\ 1,2 Jl.Bung Karno No.60 Kota Mataram,83112 \\ E-mail : sri.wahyuningsih@ sttl.mataram.ac.id ${ }^{1)}$, nurhidayah@ @ttl.mataram.ac.id ${ }^{2)}$
}

\begin{abstract}
ABSTRAK
Kabupaten Bima yang terletak di Provinsi Nusa Tenggara Barat memiliki beraneka ragam makanan tradisonal yang juga merupakan oleh-oleh khas dari Kabupaten Bima, salah satu makanan khas yang cukup terkenal dan digemari wisatawan sebagai oleh-oleh adalah Mbohi Dungga. Mbohi Dungga merupakan salah satu sambal tradisional khas Bima yang sudah terkenal akan kenikmatannya, Mbohi dungga berbahan dasar jeruk purut yang telah diolah kemudian difermentasi lalu selanjutnya dimasak dan dikemas dengan menarik. Tujuan dari penelitian ini adalah untuk mengetahui kandungan Natrium Benzoat pada makanan tradisional khas Bima yaitu Mbohi Dungga. Terdapat 8 (delapan) sampel Mbohi Dungga yang diperiksa, sampel Mbohi Dungga yang telah diambil kemudian di periksa di laboratorium untuk melihat kandungan Natrium Benzoat pada Mbohi Dungga Tersebut. Jenis penelitian yang digunakan dalam penelitian ini adalah survei yang bersifat deskriptif yaitu menganalisis kandungan natrium benzoat pada Mbohi Dungga, sampel Mbohi Dungga yang dibeli pada Produsen di analisis menggunakan Spektrofotometer UV-VIS di Balai Laboratorium kesehatan Pengujian dan Kalibrasi Provinsi NTB. Hasil dari penelitian ini dari (8) delapan sampel Mbohi Dungga tidak ditemukan sampel yang mengandung natrium benzoat. Diharapkan kepada para produsen pembuat Mbohi Dungga untuk selalu menerapkan hygiene personal dalam setiap kegiatan dan menerapkan SOP (Standar Operasional) hygiene makanan dan minuman dalam proses pengolahan Mbohi Dungga.
\end{abstract}

Kata Kunci:, Jeruk Purut, Kabupaten Bima, Mbohi Dungga, Natrium Benzoat, Spektrofotometer UV-Vis

\section{PENDAhULUAN}

Kesehatan adalah keadaan sehat, baik secara fisik, mental, spiritual maupun sosial yang memungkinkan setiap orang untuk hidup produktif secara sosial dan ekonomis. Upaya kesehatan diselenggarakan dalam bentuk kegiatan dengan pendekatan promotif, preventif kuratif, rehabilitatif yang dilaksanakan secara terpadu, menyeluruh, dan berkesinambungan.

Dalam rangka peningkatan derajat kesehatan pemerintah telah melakukan berbagai usaha sebagaimana disebutkan dalam Undang-undang kesehatan No 36 Tahun 2009 pasal 47 bahwa upaya kesehatan diselenggarakan melalui 17 macam kegiatan, salah satunya adalah pengamanan zat aditif. (Afifah A.D, dkk 2020)

Pemakaian bahan pengawet dari satu sisi menguntungkan karena dengan bahan pengawet, bahan pangan dapat dibebaskan dari mikroba. Baik bersifat patogen yang dapat menyebabkan keracunan atau gangguan kesehatan lainnya maupun microbial yang non patogen yang dapat menyebabkan kerusakan bahan pangan, misalnya pembusukan. Namun di sisi lain, bahan pengawet pada dasarnya adalah senyawa kimia yang merupakan bahan asing yang masuk bersama bahan pangan yang dikonsumsi. Apabila mengkonsumsi bahan tambahan pangan yang dosisnya tidak diatur dan diawasi, kemungkinan besar dapat menimbulkan kerugian bagi pemakainya, baik yang bersifat langsung misalnya keracunan ataupun yang tidak bersifat langsung atau kumulatif misalnya apabila bahan pengawet yang digunakan bersifat karsinogenik.

Dalam kehidupan sekarang ini banyak dijumpai pemakaian bahan pengawet secara luas, sebagai contoh, bahan pangan keluaran pabrik pada umumnya menggunakan bahan tambahan pangan (food additives) termasuk di dalamnya bahan pengawet secara sengaja ditambahkan agar bahan pangan yang dihasilkan dapat mempertahankan kualitasnya dan memiliki umur simpan lebih lama sehingga memperluas jangkauan distribusi nya (Wisnu, 2019).

Menurut Undang-Undang RI No.7 Tahun 1996 tentang pangan, pada Bab II Pasal 10 dicantumkan,(1) “ setiap orang yang memproduksi pangan untuk diedarkan dilarang menggunakan bahan apapun sebagai bahan tambahan pangan yang dinyatakan terlarang atau melampaui ambang batas maksimal yang telah ditetapkan. (2) "Pemerintah menetapkan lebih lanjut bahan yang dilarang dan atau dapat digunakan sebagai bahan tambahan pangan dan kegiatan atau proses produksi pangan serta ambang batas maksimal 
sebagaimana dimaksud pada ayat (1) (Jannah,O.Z,dkk 2021)

Sebagai salah satu kota yang berada di tepian laut, Kabupaten Bima menjadi salah satu pilihan untuk destinasi wisata dari wisatawan baik wisatawan lokal maupun mancanegara. Kabupaten Bima merupakan salah satu Daerah Otonom di Provinsi Nusa Tenggara Barat, terletak di ujung timur dari Pulau Sumbawa bersebelahan dengan Kota Bima (pecahan dari Kota Bima). Secara geografis Kabupaten Bima berada pada posisi $117^{\circ} 40^{\prime \prime}$ $119^{\circ} 10^{\prime \prime}$ Bujur Timur dan $70^{\circ} 30^{\prime \prime}$ Lintang Selatan. Selain terkenal dengan tempat wisata nya, kabupaten Bima juga terkenal dengan berbagai macam kuliner tau makanan khas nya, salah satunya Mbohi Dungga.

Mbohi Dungga merupakan penganan yang berbahan dasar jeruk purut, setelah diolah dengan berbagai macam bahan pendukung lainnya, Mbohi Dungga tersebut lalu difermentasi sehingga menghasilkan rasa yang menggugah selera. Seiring perkembangan iptek, masyarakat yang dikhawatirkan dengan menyebarnya isu bahwa Mbohi Dungga yang dibuat di kabupaten bima menggunakan pengawet sehingga dapat bertahan dalam kurun waktu yang relative lama.

Penambahan bahan tambahan makanan ke dalam produk makanan diperlukan untuk meningkatkan mutu sehingga produk makanan tersebut dapat bersaing di pasaran . Bahan Tambahan Pangan (BTP) merupakan bahan yang ditambahkan ke dalam makanan dengan maksud untuk memengaruhi sifat ataupun bentuk pangan atau produk makanan, baik yang memilki nilai gizi atau tidak memiliki nilai gizi (Ulya, M., Aronika, N. F., \& Hidayat, K. 2020). Menurut FAO (Food and Agriculture Organization), bahan tambahan pangan adalah senyawa yang sengaja ditambahkan ke dalam makanan dengan jenis dan ukuran tertentu serta terlibat dalam proses pengolahan, pengemasan, dan penyimpanan. Bahan ini berfungsi untuk memperbaiki warna, bentuk, cita rasa, dan tekstur, serta memperpanjang masa simpan, dan bukan merupakan bahan (ingredient). (Kusuma W, R,dkk 2021)

Menurut Permenkes RI No.33 Tahun 2012 tentang Bahan Tambahan Pangan, bahan pengawet adalah bahan tambahan pangan yang mencegah atau menghambat fermentasi, pengasaman, atau peruraian lain terhadap pangan yang disebabkan oleh mikroorganisme. Bahan pengawet adalah senyawa yang mampu menghambat dan menghentikan proses fermentasi, pengasaman atau bentuk kerusakan lainnya, atau bahan yang dapat memberikan perlindungan bahan pangan dari pembusukan. Bahan tambahan pangan ini ditambahkan ke dalam makanan yang mudah rusak, atau makanan yang disukai sebagai media tumbuhnya bakteri atau jamur, misalnya pada produk daging, buah-buahan.

Asam Benzoat merupakan bahan pengawet yang luas penggunaannya dan sering digunakan pada bahan makanan yang asam. Karena kelarutan garamnya lebih besar, maka biasa digunakan dalam bentuk garamnya/natrium benzoat. Mekanisme kerja natrium benzoat sebagai bahan pengawet adalah berdasarkan permeabilitas membran sel mikroba terhadap molekulmolekul asam benzoat. Penggunaan bahan pengawet natrium benzoat tidak selalu aman terutama jika digunakan dalam jumlah yang berlebihan. (Afifah Azmi,dkk, 2020)

Diketahui 8 dari 11 sampel yang kandungan natrium benzoat nya sudah memenuhi syarat kesehatan. Dimana jumlahnya sesuai dengan Permekes No. 722/Menkes/Per/IV/1988.

Berdasarkan latar belakang diatas, peneliti tertarik untuk memeriksa kadar natrium benzoat pada sambal tradisional khas bima yaitu Mbohi Dungga, hal ini dikarenakan Mbohi Dungga menjadi salah satu oleh-oleh khas bima yang sangat digemari oleh masyarakat, baik masyarakat lokal maupun wisatawan.

\section{RUANG LINGKUP}

Ruang Lingkup dalam Penelitian ini adalah untuk mengetahui kadar atau kandungan natrium benzoat pada sambal tradisional khas bima Mbohi Dungga: Sambal Jeruk yang difermentasi. Pada Penelitian ini, peneliti menggunakan Spektrofotometer Uv-Vis tipe Single Beam untuk mengetahui jumlah kadar atau jumlah kandungan Natrium Benzoat yang ada pada sambal tradisional khas Bima Mbohi Dungga : Sambal Jeruk yang difermentasi.

\section{BAHAN DAN METODE}

Pada bagian ini menjelaskan bahan-bahan dan metode apa yang akan digunakan dalam penelitian ini, di antaranya :

\subsection{Alat dan Bahan}

Alat yang digunakan adalah Erlenmeyer (Pyrex), corong pisah (Pyrex), gelas ukur (Pyrex), neraca analitik (KERN ALJ 220-4 NM), pipet mikro 100- 1000 mikro (Socorex isba S.A), Spektrofotometri UV-Vis tipe Single Beam. Bahan yang digunakan adalah Bahan baku pembanding natrium benzoat, eter, $\mathrm{HCl} 1 \mathrm{M}, \mathrm{NaCl}$, $\mathrm{NaOH} 10 \%, \mathrm{NH} 4 \mathrm{OH}, \mathrm{FeCl} 35 \%$, etanol PA, aquades, kertas saring, sampel Mbohi Dungga.

\subsection{Prosedur Kerja}

Prosedur kerja yang pertama diawali dengan Persiapan sampel, lalu dilanjutkan dengan Analisis Kualitatif dan dilanjutkan dengan analisis Kuantitatif.

1. Persiapan Sampel

Sampel Mbohi Dungga diambil sebanyak 8 sampel dari pusat penjualan yang berbeda. Sampel Mbohi Dungga dari masing-masing kemasan ditimbang sebanyak $150 \mathrm{~g}$ dan ditambahkan $300 \mathrm{~mL}$ larutan $\mathrm{NaCl}$ jenuh sambil diaduk. Kemudian sampel ditambahkan $15 \mathrm{~g} \mathrm{NaCl}$ yang telah dihaluskan dan suspensi $\mathrm{Ca}(\mathrm{OH}) 25 \%$ sampai alkalis terhadap kertas lakmus. Larutan hasil dipindahkan ke labu ukur 500 $\mathrm{mL}$ lalu ditambah sampai tanda batas kalibrasi dengan larutan $\mathrm{NaCl}$ jenuh. Larutan didiamkan 
selama lebih kurang 2 jam sambil sesekali dikocok, kemudian disaring. Filtrat di pipet sebanyak $100 \mathrm{~mL}$ kemudian dimasukkan ke dalam corong pemisah. Filtrat ditambahkan larutan $\mathrm{HCl}(1: 3)$ sampai netral terhadap kertas lakmus. Setelah larutan netral, ditambahkan kembali $5 \mathrm{~mL}$ larutan $\mathrm{HCl}$ (1:3).

2. Analisis Kualitatif Natrium Benzoat

Filtrat hasil dari ekstraksi sampel ditambahkan larutan $\mathrm{NH} 4 \mathrm{OH}$ 5\% sampai larutan tersebut menjadi basa terhadap kertas lakmus. Larutan dipindahkan ke dalam cawan porselen, kemudian di atas penangas air larutan tersebut diuapkan. Residu yang didapat dilarutkan dalam $10 \mathrm{~mL}$ air panas, lalu disaring. Filtrat ditambah 3-4 tetes larutan $\mathrm{FeCl} 3$ 5\%. Jika terbentuk endapan berwarna jingga kekuningan atau kecokelatan menunjukkan filtrat positif mengandung natrium benzoat. Berdasarkan hasil Analisis Kualitatif pada sampel Mbohi Dungga tidak terbentuk endapan berwarna jingga kekuningan atau kecokelatan (Bening).

3. Analisis Kuantitatif Natrium Benzoat

Sebanyak $1 \mathrm{~g}$ sampel ditimbang dengan teliti dan dimasukkan ke dalam gelas kimia $100 \mathrm{~mL}$ kemudian ditambahkan larutan $\mathrm{NaCl}$ jenuh hingga $20 \mathrm{~mL}$, ditambahkan dengan $\mathrm{HCl}$ sampai bersifat asam (kertas lakmus biru menjadi merah) selanjutnya di homogenkan sampai sempurna. Dimasukkan ke dalam corong pemisah, pertama diekstraksi dengan 7,5 mL dietil eter terbentuk 2 lapisan yaitu lapisan atas atau lapisan eter dipisahkan ke dalam gelas Erlenmeyer sedangkan ekstrak eter dimasukkan ke dalam corong pemisah dan dicuci dengan $5 \mathrm{~mL} \mathrm{HCl}$ $0,1 \%$, lapisan bawah dibuang dan lapisan atas dicuci lagi dengan $4 \mathrm{~mL} \mathrm{HCl} 0,1 \%$ dan seterusnya

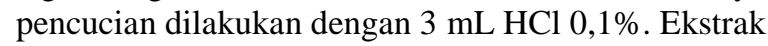
eter dimasukkan ke dalam labu takar $50 \mathrm{ml}$ dan di sesuaikan sampai garis batas dengan etanol $70 \%$ dan di homogenkan. Kemudian larutan di uap di lemari asam, residu yang didapat dilarutkan dengan etanol 96\%. Proses ini dilakukan pengulangan sebanyak dua kali. Larutan yang didapat dibaca absorbansi nya dengan menggunakan spektrofotometer UV-Vis pada panjang gelombang maksimum, kemudian konsentrasi asam benzoat dalam sampel ditentukan berdasarkan kurva standar. Pada penelitian ini tidak dilakukan pembuatan kurva standar karena tidak terdapat kandungan natrium benzoat pada sampel.

\subsection{Analisis Data}

Analisis kadar natrium benzoat dilakukan dengan perhitungan sebagai berikut : Kadar natrium benzoat dihitung dalam $\mathrm{g} / \mathrm{kg}$ Kesetaraan $=1 \mathrm{~mL} 1 \mathrm{~N} \mathrm{NaOH}$ setara dengan $144 \mathrm{mg}$ Na-Benzoat (Standar Nasional Indonesia 01-2894-1992) Hasil analisis kadar natrium benzoat tersebut kemudian dibandingkan dengan batas maksimum natrium benzoat dalam SNI 01-0222-1995 yang sebesar $1 \mathrm{~g} / \mathrm{kg}$. Hasil Pemeriksaan kadar Natrium Benzoat pada Mbohi Dungga terdapat pada Tabel 1.
Tabel 1. Hasil Pemeriksan kadar Natrium Benzoat pada Mbohi Dungga

\begin{tabular}{|c|c|c|}
\hline Sampel & $\begin{array}{c}\text { Hasil } \\
\text { Pengamatan }\end{array}$ & Keterangan \\
\hline A & Negatif & $\begin{array}{c}\text { Tidak Terdapat } \\
\text { Endapan Berwarna } \\
\text { Kecokelatan }\end{array}$ \\
\hline B & Negatif & $\begin{array}{c}\text { Tidak Terdapat } \\
\text { Endapan Berwarna } \\
\text { Kecokelatan }\end{array}$ \\
\hline $\mathrm{C}$ & Negatif & $\begin{array}{c}\text { Tidak Terdapat } \\
\text { Endapan Berwarna } \\
\text { Kecokelatan }\end{array}$ \\
\hline D & Negatif & $\begin{array}{c}\text { Tidak Terdapat } \\
\text { Endapan Berwarna } \\
\text { Kecokelatan }\end{array}$ \\
\hline $\mathrm{E}$ & Negatif & $\begin{array}{c}\text { Tidak Terdapat } \\
\text { Endapan Berwarna } \\
\text { Kecokelatan }\end{array}$ \\
\hline $\mathrm{F}$ & Negatif & $\begin{array}{c}\text { Tidak Terdapat } \\
\text { Endapan Berwarna } \\
\text { Kecokelatan } \\
\end{array}$ \\
\hline G & Negatif & $\begin{array}{c}\text { Tidak Terdapat } \\
\text { Endapan Berwarna } \\
\text { Kecokelatan }\end{array}$ \\
\hline $\mathrm{H}$ & Negatif & $\begin{array}{c}\text { Tidak Terdapat } \\
\text { Endapan Berwarna } \\
\text { Kecokelatan } \\
\end{array}$ \\
\hline
\end{tabular}

\subsection{Spektrofotometer UV Vis}

Spektrofotometer sesuai dengan namanya adalah alat yang terdiri dari spektrometer dan fotometer. Spektrometer menghasilkan sinar dari spektrum dengan panjang gelombang tertentu dan fotometer adalah alat pengukur intensitas cahaya yang ditransmisikan atau yang di absorpsi. Jadi spektrofotometer digunakan untuk mengukur energi secara relatif jika energi tersebut ditransmisikan, direfleksikan atau di emisikan sebagai fungsi dari panjang gelombang.

Cara kerja spektrofotometer secara singkat adalah sebagai berikut; Tempatkan larutan pembanding, misalnya blangko dalam sel pertama sedangkan larutan yang akan dianalisis pada sel kedua. Kemudian pilih foto sel yang cocok $200 \mathrm{~nm}-650 \mathrm{~nm}$ agar daerah $\lambda$ yang diperlukan dapat terliput. Dengan ruang foto sel dalam keadaan tertutup "nol" galvanometer di dapat dengan menggunakan tombol dark-current. Pilih $\lambda$ yang diinginkan, buka foto sel dan lewatkan berkas cahaya pada blangko dan "nol" galvanometer didapat dengan memutar tombol sensitivitas. Dengan menggunakan tombol transmitans, kemudian atur besarnya pada $100 \%$. Lewatkan berkas cahaya pada larutan sampel yang akan dianalisis. Skala absorbansi menunjukkan absorbansi larutan sampel. 


\section{PEMBAHASAN}

Mbohi Dungga merupakan salah satu Olahan sambal tradisional khas bima yang berbahan dasar jeruk purut, setelah dimasak dengan bahan lainnya sambal tersebut lalu difermentasi selama dua hari. Jeruk purut adalah salah satu kekayaan hayati Indonesia yang bisa tumbuh di berbagai daerah, baik sebagai tanaman pengisi lahan kebun maupun di halaman rumah. Jeruk purut mengandung komponen tannin, steroid triterpenoid, saponin, dan minyak atsri yang mengandung asam sitrat.

Lama penyimpanan Mbohi Dungga bisa berbulanbulan bahkan bisa sampai setahun, hal ini karena adanya minyak atsiri dalam jeruk Purut yang memiliki kandungan asam sitrat. Asam sitrat merupakan asam organik lemah yang ditemukan pada daun dan buah tumbuhan genus Citrus (jeruk-jerukan).Asam sitrat yang dihasilkan saat proses fermentasi dapat membunuh mikroorganisme dan fungi yang akan tumbuh pada makanan, sehingga makanan dapat lebih awet dan tahan lama. Sitrus atau yang dikenal dengan jeruk adalah salah satu tanaman yang mempunyai nilai ekonomi tinggi karena mengandung vitamin $\mathrm{C}$ dan digunakan sebagai penyedap masakan. Terdapat senyawa bioaktif seperti minyak atsiri, flavonoid, saponin, dan steroid dalam daun jeruk. (Hadriyati, A. 2020)

Pengawet merupakan bahan tambahan makanan dan minuman yang dapat mencegah atau menghambat penguraian terhadap makanan yang disebabkan oleh mikroorganisme. Bahan tambahan makanan dan minuman ini ditambahkan ke dalam makanan yang mudah rusak, atau makanan dan minuman yang disukai sebagai medium tumbuhnya bakteri atau jamur. Pemakaian bahan pengawet dengan dosis yang tidak diatur dan diawasi, kemungkinan besar akan menimbulkan kerugian bagi yang mengkonsumsi, baik yang bersifat langsung misalnya keracunan ataupun yang bersifat tidak langsung misalnya apabila bahan pengawet yang digunakan bersifat karsinogenik . (Febrianti, R,D. 2020)

Natrium benzoat memiliki nama resmi NATRII BENZOAS dengan rumus molekul C7H5NaO2 dan berat molekul sebesar 114. Pemerian nya berupa butiran atau serbuk hablur putih tidak berbau atau hampir tidak berbau, kelarutan dalam 2 bagian air dan dalam 90 bagian etanol (95\%). Penyimpanan dalam wadah tertutup baik, penggunaannya sebagai zat tambahan (Sjarif, S. R.,dkk, 2019)

Dalam penggunaannya, asam benzoat kurang kelarutan nya dalam air dibandingkan dalam bentuk garamnya, sehingga pemakaiannya sering digunakan dalam bentuk garamnya yaitu natrium benzoat.

Natrium benzoat merupakan salah satu bahan pengawet yang umum digunakan untuk mengawetkan berbagai makanan dan minuman seperti sari buah, minuman ringan, saus tomat, jelly, manisan, kecap dan lain-lain. Manisan buah cepat rusak akibat suhu yang tinggi. Oleh karena itu produsen manisan buah menggunakan pengawet. Salah satu bahan pengawet yang digunakan untuk mengawetkan manisan buah adalah natrium benzoat. Alasan para produsen manisan buah menggunakan pengawet natrium benzoat karena natrium benzoat mudah dijumpai serta penggunaan natrium benzoat yang mudah. Natrium benzoat yang berbentuk kristal bisa langsung ditaburkan kedalam manisan buah. Sebagai alternatif untuk mengawetkan manisan buah dapat menggunakan larutan gula pasir sebagai pengawet (Asmawati S, A., \& Sinala, S. 2019).

Natrium benzoat merupakan garam asam Sodium Benzoic, yaitu lemak tidak jenuh ganda yang telah disetujui penggunaannya oleh FDA (Food and Drug Administration) dan telah digunakan oleh para produsen makanan dan minuman. Penggunaan Benzoat di dalam tubuh manusia di absorbsi dari usus halus dan di aktivasi melalui ikatan dengan CoA untuk menghasilkan benzoyl coenzyme A. Selanjutnya benzoyl coenzyme A terkonjugasi dengan glisin dalam hati untuk membentuk asam hipurat yang kemudian dikeluarkan melalui urine. (Rahmania, N., Hadriyati, A. dkk, 2020).

Berdasarkan Permenkes RI No.
722/Menkes/Per/IX/88 dan No. 1168/ Menkes/Per/X/1999 batas maksimal penggunaan asam benzoat dan natrium benzoat adalah $0,1 \%$ atau 1 gram asam benzoat setiap $1 \mathrm{~kg}$ bahan makanan. Menurut Peraturan BPOM No.36 Tahun 2013, asupan harian yang dapat diterima atau Acceptable Daily Intake natrium benzoat adalah $0-5 \mathrm{mg} / \mathrm{kg}$ berat badan. (Ayu, K , dkk 2020)

Batas aman penggunaan natrium benzoat pada makanan dan minuman sudah diatur oleh berbagai organisasi di dunia bahkan di Indonesia. Dari Food and Drug Administration (FDA), natrium benzoat direkomendasikan sebagai GRAS (Generally Recognized A Safe) dengan batas maksimum konsentrasi yang diizinkan $0,1 \%$ (Khade \& Mirgane, 2014). Penggunaan batas maksimum natrium benzoat sebagai bahan tambahan pangan di Indonesia sudah diatur dalam Peraturan Kepala BPOM RI Nomor 36 Tahun 2013 yaitu 600 mg/kg. (Armini A,dkk 2020).

Penggunaan natrium benzoat sebagai bahan pengawet seringkali disalahgunakan, seperti penggunaan yang melebihi batas maksimum yang diizinkan. Dari 3 sampel minuman isotonik yang ditelitinya, hanya satu merek minuman isotonik yang mengandung natrium benzoat (Supriyatin, 2019). Penggunaan natrium benzoat secara terus-menerus dampaknya baru akan terasa beberapa waktu kemudian setelah terakumulasi dalam tubuh karena natrium benzoat bersifat karsinogen di dalam tubuh (Armini A,dkk 2020).

Ambang penggunaan bahan pengawet yang diizinkan adalah batasan dimana konsumen tidak menjadi keracunan dengan tambahan pengawet tersebut. Penambahan pengawet memiliki risiko bagi kesehatan tubuh, jika terakumulasi terus menerus dalam waktu yang lama sehingga menimbulkan gangguan di berbagai organ. (Faroch D,dkk 2021) 
Efek samping lain yang bisa timbul adalah edema akibat dari retensi cairan di dalam tubuh dan meningkatnya tekanan darah sebagai akibat bertambahnya volume plasma akibat pengikatan air oleh natrium. Selain itu, menurut Penelitian Lembaga Konsumen Jakarta (LKJ) terdapat hubungan konsumsi makanan dan minuman yang mengandung natrium benzoat dengan pasien Penyakit Systemic Lupus Erythematous (SLE) yang berobat di Rumah Sakit Hasan Sadikin, Bandung.(Sjarif, S. R, dkk, 2019)

Metabolisme natrium benzoat yang masuk ke dalam tubuh akan melewati membran-membran tubuh manusia dan memasuki aliran darah karena tidak ada system yang khusus pada manusia untuk tujuan tunggal mengenai penyerapan zat-zat kimia. Natrium benzoat di absorbsi dari usus halus dan di aktivasi melalui ikatan CoA untuk menghasilkan benzoyl coenzyme A. selanjutnya benzoyl coenzyme A terkonjugasi dengan glisin dalam hati untuk membentuk asam hipurat yang kemudian dikeluarkan melalui urine. Oleh karena itu, dianjurkan agar banyak meminum air putih untuk membantu proses hidrolisa yang berfungsi sebagai ekskresi. Pengkonsumsian natrium benzoat yang berlebihan dapat menyebabkan mual, sakit kepala dan iritasi tenggorokan. Natrium benzoat yang masuk ke dalam tubuh akan masuk ke aliran darah, diserap oleh lambung dan dapat mengiritasi lambung. Pemberian batas maksimum terhadap natrium benzoat dilakukan karena penggunaan bahan pengawet natrium benzoat tidak selalu aman terutama jika digunakan dalam jumlah yang berlebihan dapat menyebabkan keram perut, rasa kebas di mulut, bagi mereka yang mengalami lelah atau mempunyai penyakit ruam. Pengawet ini bersifat menumpuk sehingga berpotensi menimbulkan penyakit kanker dan dapat merusak sistem saraf. Pemakaian bahan pengawet dari satu sisi menguntungkan karena bahan makanan dapat dibebaskan dari kehidupan mikroba sehingga makanan dapat tahan lebih lama. Namun dari sisi lain bahan pengawet pada dasarnya adalah senyawa kimia yang merupakan bahan asing yang masuk bersama bahan makanan yang dikonsumsi. Apabila pemakaian bahan pengawet tidak diatur dosisnya dan diawasi kemungkinan besar akan menimbulkan kerugian bagai pemakainya, baik yang bersifat langsung misalnya keracunan atau pun yang bersifat tidak langsung atau kumulatif bersifat karsinogenik. (Suryani H, 2019)

Dari hasil pemeriksaan ke 8 (delapan) sampel Mbohi Dungga menggunakan Spektrofotometer UV-Vis ,tidak ditemukan kandungan natrium benzoate di dalamnya, hal ini dikarenakan rata-rata produsen pembuat Mbohi dungga sudah mengetahui tentang bahaya penggunaan pengawet untuk kesehatan, selain itu tanpa harus menggunakan pengawet Mbohi Dungga juga bisa bertahan lama karena terdapat senyawa asterin di dalam jeruk purut.

Analisis kandungan natrium benzoat pada manisan buah serta tingkat pengetahuan pedagang di pasar rahmat tahun 2018 diperoleh hasil manisan sebagian besar tidak mengadung Natrium Benzoat (Rismawati Sirait, 2018).

Sampel selai stroberi curah yang diperdagangkan di beberapa pasar tradisional Kecamatan Jebres Surakarta tidak semuanya positif mengandung natrium benzoat (Chintya Putri Wiradika dan Petrus Darmawan, 2019) Berdasarkan hasil penelitian dapat disimpulkan bahwa.

Spektrofotometri adalah ilmu yang mempelajari tentang penggunaan spektrofotometer. Spektrofotometer adalah alat yang terdiri dari spektrofotometer dan fotometer. Spektrofotometer adalah alat yang digunakan untuk mengukur energi secara relatif jika energi tersebut ditransmisikan, direfleksikan, atau di emisikan sebagai fungsi dari panjang gelombang. Spektrofotometer menghasilkan sinar dari spektrum dengan panjang gelombang tertentu, dan fotometer adalah alat pengukur intensitas cahaya yang ditransmisikan atau yang di absorpsi.

Kelebihan spektrofotometer dibandingkan dengan fotometer adalah panjang gelombang dari sinar putih dapat lebih terseleksi dan ini diperoleh dengan alat pengurai seperti prisma, grating ataupun celah optis. Pada fotometer filter, sinar dengan panjang gelombang yang diinginkan diperoleh dengan berbagai filter dengan berbagai warna yang mempunyai spesifikasi melewatkan trayek panjang gelombang tertentu. Pada fotometer filter, tidak mungkin diperoleh panjang gelombang yang benarbenar monokromatis, melainkan suatu trayek panjang gelombang 30-40 nm. Sedangkan pada spektrofotometer, panjang gelombang yang benar-benar terseleksi dapat diperoleh dengan bantuan alat pengurai cahaya seperti prisma. Suatu spektrofotometer tersusun dari sumber spectrum tampak yang kontinyu, monokromator, sel mengabsorpsi untuk larutan sampel dan blangko ataupun pembanding. (Great B, dkk 2018)

Suatu spektrofotometer tersusun dari sumber spektrum tampak yang kontinyu, monokromator, sel pengabsorbsi untuk larutan sampel atau blangko dan suatu alat untuk mengukur perbedaan absorbsi antara sampel dan blangko ataupun pembanding (Great B,dkk 2018).

\section{KESIMPULAN}

Dari ke 8 (delapan) sampel Mbohi Dungga yang diperiksa tidak terdapat kadar atau kandungan natrium benzoat di dalamnya. Sambal tradisional khas Bima Mbohi Dungga: Sambal jeruk yang difermentasi bisa bertahan lama karena adanya kandungan minyak astiri di dalam jeruk purut, dimana jeruk purut merupakan bahan utama pembuatan Mbohi Dungga.

\section{SARAN}

Saran untuk peneliti selanjutnya agar bisa melakukan pemeriksaan hygienists bahan-bahan yang digunakan dalam proses pembuatan sambal tradisional khas bima Mbohi Dungga: Sambal Jeruk yang difermentasi. 


\section{DAFTAR PUSTAKA}

Afifah A, D., \& Fitri, F. 2020. Identifikasi Kualitatif Dan Kuantitatif Natrium Benzoat Pada Saus Cabai Yang Dijual Di Beberapa Pasar Di Kota Padang. In Jurnal Kesehatan Andalas (Vol. 9). Http://Jurnal.Fk.Unand.Ac.Id

Asmawati S, A., \& Sinala, S. 2019. Analisis Kadar Natrium Benzoat Saos Tomat Jajanan Makanan Di Lingkungan Kampus Stikes Pelamonia Makassar Dengan Metode Spektrofotometri Uv-Vis Analysis Of Sodium Levels Benzoat Saos Food Tomato In The Campus Environment O Stikes Pelamonia Makassar By Uv-Visible Spectrophotometry Method. In Jurnal Penelitian Kesehatan Pelamonia Indonesia (Vol. 02).

Ayu, K., Dewi, Y, Ayu, D., Pramitha, I., \& Juliadi, D. (N.D.). 2020. Penetapan Kadar Pengawet Natrium Benzoat Pada Sambal Kemasan Secara Spektrofotometri Uv-Vis Penetapan Kadar Pengawet Natrium Benzoat Pada Sambal Kemasan Secara Spektrofotometri Uv-Vis (Determination Of Sodium Benzoate Content In Packaged Chili Sauce Using Uv-Vis Spectrophotometry).

D., Faroch, U., Dhanti, K. R., Sudarsono, T. A., \& Purwokerto, M. 2021. Analisis Kadar Natrium Benzoat Pada Saus Sambal Di Pasar Wage Kabupaten Banyumas. Universitas Muhammadiyah Semarang. Semarang Indonesia, 5,25 .

Febrianti, R,D. 2020 .Uji Aktivitas Antibakteri Minyak Atsiri Buah Jeruk Purut (Citrus Hystrix D.C) Terhadap Staphylococcus Aureus Dan Escherichia Coli. 2009.

Febrianti, D. R., \& Ariani, N. 2020. Uji Potensi Minyak Atsiri Daun Jeruk Purut (Citrus Hystrix D.C) Sebagai Antioksidan Dan Antibakteri. Jurnal Insan Farmasi Indonesia, 3(1), 66-74. Https://Doi.Org/10.36387/Jifi.V3i1.458

Great B. Parliament. House Of Commons. Environment, T. 2018. Health \& Safety Commission And Executive Response To The First Report Of The Committee : Railway Safety: First Special Report ... Stationery Office.

Hadriyati, A. 2020. Analysis Of Sodium Benzoate Levels In Cinnamon Syrup Using High Performance Liquid Chromatography Method. Jurnal Kartika Kimia, 3(2). Https://Doi.Org/10.26874/Jkk.V3i2.55

Hadriyati, A., Retnasari, A., Pratama, S., \& Penulis, K. 2020. Analisis Kadar Natrium Benzoat Pada Bumbu Jahe Giling (Zingiber Officinale) Di Pasar Tradisional Jambi Analysis Of Sodium Benzoate Levels In Ground Ginger (Zingiber Officinale) In The Traditional Jambi Market. In Journal of Healthcare Technology And Medicine (Vol. 6, Issue 1).

Jannah, O. Z., Komang Suwita, I., Jayadi, L., Farmasi,
A., Makanan, D., Kementerian, K., \& Malang, K. (N.D.). Analisis Pewarna Rhodamin B Dan Pengawet Natrium Benzoat Pada Saus Tomat Yang Diperdagangkan Di Pasar Besar Tradisional Kota Malang. $\quad 3(1), \quad 2021$. Https://Doi.Org/10.33759/Jrki.V2i3.105

Kusuma W, R., Rahayu, C., Gizi, J., Kemenkes, P., Raya, P., \& Tengah, K. 2021. Analisis Keberadaan Rhodamin B Dan Natrium Benzoat Dalam Saus Tomat Pentol Di Kota Palangka Raya. J. Sains Dan Teknologi Pangan, 6(3), 4011-4019.

Luwitono, C. P. W. D., \& Darmawan, P. 2019. Analisis Pengawet Natrium Benzoat Pada Selai Stroberi Curah Di Pasar Tradisional. Biomedika, 12(2), 244-250.

Https://Doi.Org/10.31001/Biomedika.V12i2.533

Nurman, S., \& Muhardina, V. 2018. Pengaruh Konsentrasi Natrium Benzoat Dan Lama Penyimpanan Terhadap Mutu Minuman Sari Nanas (Ananas Comosus L.) (Vol. 15, Issue Desember).

Rahmania, N., Hadriyati, A., Sanuddin, M., Tarmizi Kadir Pakuan Baru, J., Hadriyanti, A., \& Sannudin, M. 2020. Analisis Natrium Benzoat Pada Saos Yang Diproduksi Di Kota Jambi Dengan Metode Spektrofotometri Uv-Vis Analysis Of Sodium Benzoates In Produced Saos In Jambi City Of Methods Spectrophotometric Uv-Vis. In Journal Of Healthcare Technology And Medicine (Vol. 6, Issue 2).

Sirait,R. 2021 .Pengawetan Dan Daya Terima Saus Nanas Sebagai Oleh-Oleh Khas Subang Skripsi Diajukan Untuk Memenuhi Sebagian Syarat Untuk Memperoleh Gelar Sarjana Di Program Studi Pendidikan Tata Boga. (N.D.).

Sjarif, S. R., Rosmaeni, A., Riset, B., Standardisasi, D., Manado, I., Besar, B., \&, I. H. 2019. Pengaruh Penambahan Bahan Pengawet Alami Terhadap Pertumbuhan Mikroba Pada Pasta Tomat Effect Of Addition Of Natural Preservatives On The Growth Of Microbial Growth In Tomato Paste. Jurnal Penelitian Teknologi Industri, 11(2), 71-82.

Suryani H, 2019. Pengujian Kadar Asam Benzoat, Asam Sorbat Dan Natrium Sakarin Pada Saus Tomat Yang Dijual Di Kota Medan Dengan Metode Kromatografi Cair Kinerja Tinggi (Kckt). (N.D.).

Ulya, M., Aronika, N. F., \& Hidayat, K. 2020. Pengaruh Penambahan Natrium Benzoat Dan Suhu Penyimpan Terhadap Mutu Minuman Herbal Cabe Jamu Cair. Rekayasa, 13(1), 77-81. Https://Doi.Org/10.21107/Rekayasa.V13i1.5385

Wisnu,W., 2018. Analisis Kandungan Natrium Benzoat Pada Manisan Buah Serta Tingkat Pengetahuan Pedagang Di Pasar Ramai Tahun 2018 Skripsi. 


\section{UCAPAN TERIMA KASIH}

Penulis mengucapkan terima kasih kepada

Direktorat Riset dan Pengabdian Masyarakat (DPRM) yang memberikan Dana Hibah Penelitian Dosen melalui

Skim Penelitian Dosen Pemula Tahun Anggaran 2021 dengan nomor kontrak Nomor : 1962/LL8/KM/2021

Ucapan terima kasih juga kepada pihak yang membantu dalam pelaksanaan penelitian dan publikasi artikel ini, dan mengarahkan penulis untuk menyempurnakan artikel. 